\title{
Skeletal Age Determinations in Children of European and African Descent: Applicability of the Greulich and Pyle Standards
}

\author{
STEFANO MORA, M. INES BOECHAT, EWA PIETKA, H. K. HUANG, AND VICENTE GILSANZ \\ Department of Radiology, Childrens Hospital Los Angeles, University of Southern California, Keck's \\ School of Medicine, Los Angeles, CA 90027, U.S.A. [S.M., V.G.]; University of California Los Angeles, \\ School of Medicine, Los Angeles, CA 90024, U.S.A. [M.I.B.]; and University of California San Francisco, \\ Department of Radiology, San Francisco, CA 94143, U.S.A. [E.P., H.K.H.]
}

\begin{abstract}
ABST
This study assesses the value of the Greulich and Pyle method
in determining the skeletal ages of healthy American children of
European and African descent born after the year 1980 . The hand
and wrist radiographs of 534 children $(265$ boys, 269 girls; 260
European-Americans [EA], 274 African-Americans [AA]), ages
0 to 19 y, were analyzed by two experienced pediatric radiolo-
gists blinded to the chronological age of the subjects. A differ-
ence score was calculated for each subject by subtracting chro-
nological age from the mean bone ages scores provided by the
two raters. One group t-tests were performed to verify the
hypothesis that the mean difference score was equal to zero.
Skeletal age determinations by the two radiologists showed a
high degree of agreement by intraclass correlation coefficient
( $\mathrm{r}=0.994)$. The range of values for differences in skeletal and
chronological ages was very wide, indicating great individual
variability. Comparisons between skeletal and chronological age
only reached statistical significance in EA prepubertal girls,
whose skeletal ages were delayed, on average, by three months
( $\mathrm{t}=-2.9 ; p=0.005)$. Mean difference between skeletal and
chronological age in prepubertal children of African descent was
$0.09 \pm 0.66$ y, while that in children of European descent was
$-0.17 \pm 0.67 \mathrm{y} ; \mathrm{t}=3.13 ; p=0.0019)$. On average, the bone
\end{abstract}
Skeletal age is a frequently used diagnostic tool for the evaluation of endocrine, orthopedic, genetic, and renal disorders, to monitor response to medical therapy and to determine the growth potential of children (1). The method most widely used for bone age determination is the reference atlas of Greulich and Pyle, consisting of radiologic examinations of the left hand and wrist from subjects at different stages of skeletal maturation (2). While this method has the advantages of sim-

\footnotetext{
Received October 11, 2001; accepted February 20, 2001.

Reprint requests: Vicente Gilsanz, MD, Radiology Department, Childrens Hospital Los Angeles, 4650 Sunset Boulevard, M.S.\# 81, Los Angeles, CA 90027; e-mail: VGilsanz@chla.usc.edu

Supported in part by a grant (1RO1 LM06270) from the National Library of Medicine. Present Address [S.M.]: Department of Pediatrics, Scientific Institute H San Raffaele, Milan, Italy.
}

ages of $10 \%$ of all prepubertal AA children were 2 SD above the normative data in the Greulich and Pyle atlas, while the bone ages of $8 \%$ of all prepubertal EA children were 2 SD below. In contrast to the racial differences observed in prepubertal children, EA postpubertal males had significantly greater values for bone age than AA postpubertal males $(\mathrm{t}=2.03 ; p=0.05)$. In conclusion, variations in skeletal maturation in prepubertal children are greater than those reflected in the Greulich and Pyle atlas; prepubertal American children of European descent have significantly delayed skeletal maturation when compared with those of African descent; and, postpubertal EA males have significantly advanced skeletal maturation when compared with postpubertal AA males. New standards are needed to make clinical decisions that require reliable bone ages and to accurately represent a multiethnic pediatric population. (Pediatr Res 50: 624-628, 2001)
AA, African-Americans
EA, European-Americans
ICC, intraclass correlation coefficient
SD, standard deviation

\section{Abbreviations}

plicity and availability of multiple ossification centers for the evaluation of maturity, it is, however, qualitative and was compiled solely from Caucasian children who lived in the 1930s. Nevertheless, the Greulich and Pyle standards are, at present, the most commonly used method for skeletal age assessments throughout the world, regardless of ethnic background $(3,4)$.

In an attempt to overcome ethnic and racial differences in skeletal maturation, standards have been developed for the German, Scandinavian and Japanese populations (5-9). However, there are still many questions regarding the applicability of the Greulich and Pyle standards to today's American children of different ethnic backgrounds. Children of the 1980s physically matured at a younger age than did those of several 
Table 1. Age and anthropometric characteristics of 534 healthy children

\begin{tabular}{|c|c|c|c|c|}
\hline & \multicolumn{2}{|c|}{ European American } & \multicolumn{2}{|c|}{ African American } \\
\hline & Girls & Boys & Girls & Boys \\
\hline$n$ & 130 & 130 & 139 & 135 \\
\hline Weight $(\mathrm{kg})$ & $39.1 \pm 18.0$ & $43.3 \pm 21.5$ & $41.4 \pm 19.5$ & $42.8 \pm 20.2$ \\
\hline Height $(\mathrm{cm})$ & $139.4 \pm 27.3$ & $144.1 \pm 30.1$ & $140.9 \pm 28.4$ & $145.0 \pm 30.0$ \\
\hline Surface Area $\left(\mathrm{m}^{2}\right)$ & $1.2 \pm 0.4$ & $1.3 \pm 0.4$ & $1.2 \pm 0.4$ & $1.3 \pm 0.4$ \\
\hline BMI $\left(\mathrm{kg} / \mathrm{m}^{2}\right)$ & $18.6 \pm 3.4$ & $19.1 \pm 3.2$ & $19.1 \pm 3.9$ & $18.9 \pm 3.1$ \\
\hline
\end{tabular}

decades ago $(1,10,11)$. Moreover, African-American children have been found to mature more quickly relative to Greulich and Pyle standards for Caucasian children, especially in the first few years of development (5-9). The present investigation determines whether the standards of the Greulich and Pyle atlas are adequate for African- and European-American children born after 1980 .

\section{SUBJECTS AND METHODS}

Study subjects. The study subjects were healthy AfricanAmerican (AA) and European-American (EA) children and adolescents who were recruited from schools in Los Angeles County. The investigational protocol was approved by the institutional review board for clinical investigations at Childrens Hospital of Los Angeles, and informed consent was obtained from all subjects and/or their parents. The subjects ranged in age from 0 to $19 \mathrm{y}$.

The children and/or their parents were asked about their racial backgrounds. Candidates were excluded if either parent or each set of grandparents were not of the same race. Candidates for this study were also excluded if they had been given a diagnosis of any chronic illness, if they had been ill for longer than two weeks during the previous six months, if they had taken any medications, vitamin preparations, or calcium supplements within the previous six months, or if they had been hospitalized at any time since birth. All subjects were appropriately physically active for their age.

Candidates for this study underwent a physical examination by a pediatric endocrinologist to determine their general health and their Tanner stage of sexual development. The grading system of Tanner utilizes assessments of the pattern of development of pubic hair in all children, of breast development in girls, and penile and testicular size in boys (12). If discrepancies existed among criteria, greater emphasis was placed on the degree of breast development, or testicular and penile size for designation of Tanner stage. Measurements of height and weight were obtained, and children in whom either height or weight were not within the 5th and 95th percentiles for the mean age-adjusted normal values were excluded from further evaluation (13). Body-surface area (SA) and body-mass index (BMI) were calculated as previously described (14).

Skeletal maturation was assessed on the basis of roentgenograms of the left hand and wrist. The radiographs were evaluated according to the method of Greulich and Pyle, and bone age was determined (2). Skeletal maturation assessments were performed independently by two senior pediatric radiologists blinded with reference to the chronological age of the subjects. Radiographs from a total of 534 children (130 EA girls, 130 EA boys, 139 AA girls, and 135 AA boys) were analyzed.

Data analysis. The concordance between the readings of the two pediatric radiologists was evaluated by computing the intraclass correlation coefficient (ICC) (15). A difference score was calculated for each radiograph by subtracting the chronological age from the mean bone age scores provided by the two raters. The difference scores were analyzed according to race and gender. Moreover, they were stratified according to the degree of sexual maturation as prepubertal (Tanner I), pubertal (Tanner II, III, IV), and postpubertal (Tanner V). In each subgroup, a one-group $t$ test was used to verify the null hypothesis that the mean difference score was equal to zero. Data are expressed as mean $\pm \mathrm{SD}$, unless otherwise stated. All

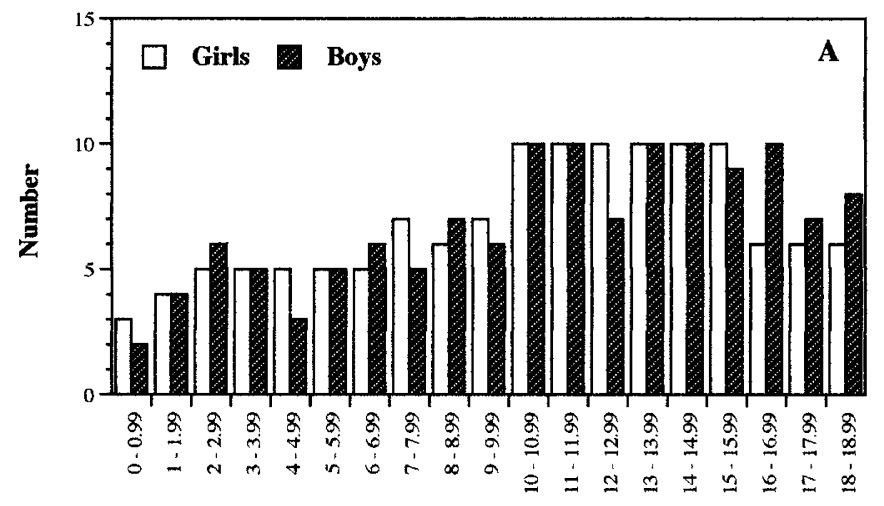

Age Range

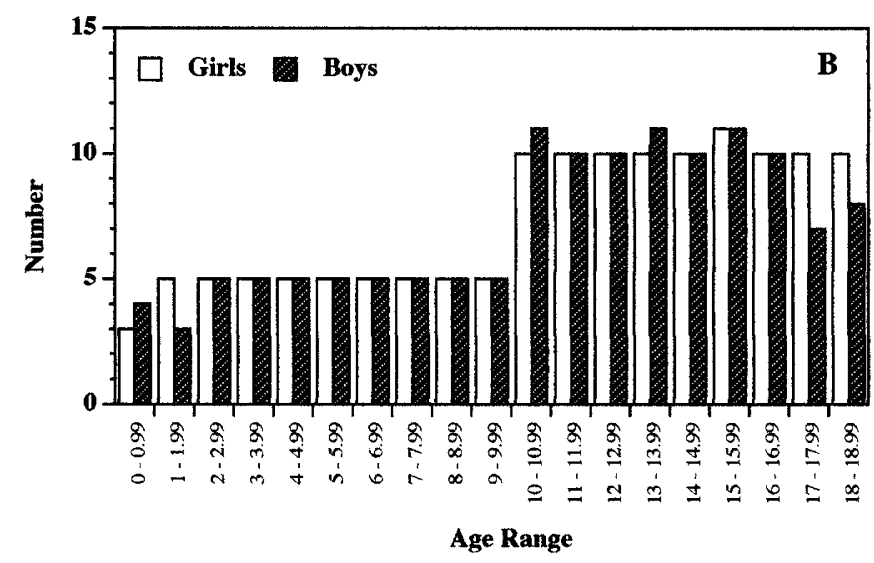

Figure 1. Number and age distribution of radiographs obtained from 534 healthy children. $(A)$ shows EA subjects; $(B)$ shows AA subjects. 
Table 2. Chronological age, bone age, weight, and height in healthy American girls of African and European descent grouped by Tanner stage of sexual development

\begin{tabular}{|c|c|c|c|c|c|c|c|c|c|c|}
\hline \multirow[b]{2}{*}{ Tanner } & \multicolumn{5}{|c|}{ African-American Girls } & \multicolumn{5}{|c|}{ European-American Girls } \\
\hline & $n$ & Chron. age (y) & Bone age (y) & Weight $(\mathrm{kg})$ & Height $(\mathrm{cm})$ & $n$ & Chron. age (y) & Bone age (y) & Weight $(\mathrm{kg})$ & Height $(\mathrm{cm})$ \\
\hline I & 56 & $5.6 \pm 3.2$ & $6.0 \pm 3.1$ & $22.0 \pm 10.5$ & $112.9 \pm 24.7$ & 62 & $6.6 \pm 3.3$ & $6.3 \pm 3.2$ & $23.5 \pm 9.9$ & $117.4 \pm 23.5$ \\
\hline $4-8$ & 20 & $6.1 \pm 1.2$ & $6.0 \pm 1.2$ & $21.6 \pm 4.9$ & $115.9 \pm 8.8$ & 22 & $6.2 \pm 1.2$ & $6.0 \pm 1.2$ & $21.0 \pm 3.1$ & $116.7 \pm 7.8$ \\
\hline $8-12$ & 18 & $9.6 \pm 0.9$ & $9.6 \pm 1.1$ & $33.6 \pm 6.8$ & $139.0 \pm 8.1$ & 23 & $10.1 \pm 1.1$ & $9.6 \pm 1.4$ & $34.1 \pm 5.9$ & $140.6 \pm 7.9$ \\
\hline II & 4 & $11.8 \pm 1.6$ & $11.8 \pm 1.4$ & $42.3 \pm 0.8$ & $151.9 \pm 7.8$ & 14 & $11.5 \pm 1.2$ & $11.3 \pm 1.4$ & $43.3 \pm 5.9$ & $149.8 \pm 8.8$ \\
\hline III & 16 & $12.2 \pm 1.2$ & $12.2 \pm 1.3$ & $44.1 \pm 8.0$ & $154.6 \pm 6.9$ & 10 & $12.9 \pm 0.8$ & $13.1 \pm 1.1$ & $44.3 \pm 5.6$ & $155.8 \pm 5.9$ \\
\hline $\mathrm{V}$ & 44 & $16.5 \pm 1.6$ & $16.6 \pm 1.2$ & $61.5 \pm 10.6$ & $163.2 \pm 5.3$ & 39 & $16.1 \pm 1.6$ & $16.0 \pm 1.1$ & $59.6 \pm 7.8$ & $164.1 \pm 5.4$ \\
\hline
\end{tabular}

Table 3. Chronological age, bone age, weight, and height in healthy American boys of African and European descent grouped by Tanner stage of sexual development

\begin{tabular}{|c|c|c|c|c|c|c|c|c|c|c|}
\hline \multirow[b]{2}{*}{ Tanner } & \multicolumn{5}{|c|}{ African-American Boys } & \multicolumn{5}{|c|}{ European-American Boys } \\
\hline & $n$ & Chron. age (y) & Bone age $(y)$ & Weight $(\mathrm{kg})$ & Height $(\mathrm{cm})$ & $n$ & Chron. age (y) & Bone age (y) & Weight $(\mathrm{kg})$ & Height $(\mathrm{cm})$ \\
\hline I & 65 & $6.9 \pm 3.5$ & $7.0 \pm 3.5$ & $26.4 \pm 11.1$ & $120.6 \pm 24.0$ & 69 & $7.2 \pm 3.5$ & $7.1 \pm 3.6$ & $26.6 \pm 10.9$ & $121.2 \pm 22.5$ \\
\hline $4-8$ & 20 & $6.2 \pm 0.9$ & $6.2 \pm 1.1$ & $23.5 \pm 3.5$ & $120.4 \pm 7.9$ & 19 & $6.2 \pm 1.1$ & $5.9 \pm 1.1$ & $22.5 \pm 3.6$ & $117.4 \pm 6.1$ \\
\hline $8-12$ & 24 & $10.0 \pm 1.0$ & $10.4 \pm 1.3$ & $36.4 \pm 6.6$ & $140.9 \pm 6.3$ & 30 & $10.1 \pm 1.1$ & $10.0 \pm 1.7$ & $34.9 \pm 7.2$ & $138.7 \pm 9.2$ \\
\hline$>12$ & 4 & $12.3 \pm 0.1$ & $11.2 \pm 0.3$ & $38.8 \pm 8.8$ & $146.4 \pm 5.4$ & 3 & $12.5 \pm 0.5$ & $12.3 \pm 0.5$ & $43.1 \pm 9.7$ & $151.8 \pm 1.9$ \\
\hline II & 9 & $12.3 \pm 1.6$ & $11.8 \pm 1.5$ & $39.9 \pm 6.1$ & $151.2 \pm 8.6$ & 5 & $12.1 \pm 1.6$ & $12.0 \pm 0.8$ & $42.5 \pm 7.8$ & $151.5 \pm 10.0$ \\
\hline $\mathrm{V}$ & 31 & $16.7 \pm 1.3$ & $16.8 \pm 1.5$ & $69.5 \pm 9.3$ & $176.8 \pm 5.9$ & 32 & $16.8 \pm 1.2$ & $17.3 \pm 1.1$ & $70.5 \pm 10.8$ & $176.2 \pm 5.9$ \\
\hline
\end{tabular}

Table 4. Differences between bone age and chronological age in healthy American children of African and European descent, grouped by stage of sexual development*

\begin{tabular}{|c|c|c|c|c|}
\hline Race and gender & $\begin{array}{c}\text { Stage of sexual } \\
\text { development }\end{array}$ & $n$ & $\begin{array}{c}\text { Mean } \pm \text { SD } \\
\text { difference (y) }\end{array}$ & Range (y) \\
\hline \multirow[t]{2}{*}{ European-American girls } & Prepubertal & 62 & $-0.24 \pm 0.66$ & -2.33 to 1.35 \\
\hline & Pubertal & 29 & $-0.10 \pm 1.09$ & -2.24 to 1.96 \\
\hline \multirow{3}{*}{ European-American boys } & Prepubertal & 69 & $-0.11 \pm 0.67$ & -2.43 to 1.53 \\
\hline & Pubertal & 27 & $0.27 \pm 0.79$ & -1.62 to 2.43 \\
\hline & Postpubertal & 34 & $0.36 \pm 1.04$ & -1.88 to 2.62 \\
\hline African-American girls & Postpubertal & 44 & $0.08 \pm 1.01$ & -3.05 to 3.02 \\
\hline \multirow[t]{3}{*}{ African-American boys } & Prepubertal & 65 & $0.12 \pm 0.68$ & -1.66 to 2.31 \\
\hline & Pubertal & 39 & $-0.32 \pm 1.14$ & -2.70 to 2.58 \\
\hline & Postpubertal & 31 & $0.12 \pm 0.72$ & -1.28 to 1.78 \\
\hline
\end{tabular}

* Positive values indicate that skeletal age is advanced compared to chronological age, and negative values indicate a delayed skeletal age compared to chronological age.

significance tests were conducted at the $\alpha=0.05$ level and were two-tailed. The computer software program JMP $\mathrm{IN}^{\circledR}$ (SAS Institute, Inc., Cary, NC) was used for the analyses.

\section{RESULTS}

The ages and anthropometric characteristics of the study group are summarized in Table 1. Mean values for bone age were similar to those for chronological age. By design, the average values for height and weight were between the 5th and 95th percentiles for age; mean heights were at or about the 25th and 50th percentiles, and mean weights were at or about the 50th and 75th percentiles, for girls and boys, respectively. Distribution of the radiographs obtained from healthy children and grouped according to gender, race, and chronological age is shown in Figs. 1A and 1B.

Analyses of bone ages by the two pediatric radiologists showed a high degree of agreement. The ICC computed separately for boys and girls were $r=0.993$ and $r=0.995$, respectively. Readings were also highly concordant when EA $(r=0.994)$ and AA subjects $(r=0.993)$ were analyzed. Because of the high level of agreement between the two radiologists, the mean between the two readings was used for further analyses.

Table 2 shows mean values for skeletal and chronological ages, height and weight, for girls of both racial groups at all Tanner stages of sexual development; Table 3 shows similar 
data for boys. Regardless of gender, no significant differences were observed between the chronological ages and the anthropometric measurements of AA and EA children at any stage of sexual development (all $p$ 's $>0.05$ ).

Table 4 indicates mean differences between skeletal and chronological ages for EA and AA children stratified according to degree of sexual development. In all subgroups, the range of values was very wide, indicating great individual variability. Comparisons between skeletal and chronological age only reached statistical significance in EA prepubertal girls. The average skeletal age in this subgroup was delayed by three months $(\mathrm{t}=-2.9 ; p=0.005)$. Differences between skeletal and chronological age were not significant in any other subgroup, regardless of gender, race, or pubertal status.

There were significant differences in skeletal maturation between AA and EA children. Compared with AA prepubertal children, EA subjects had delayed bone age; mean difference between skeletal and chronological age in prepubertal children of African descent was $0.09 \pm 0.66 \mathrm{y}$, while that in children of European descent was $-0.17 \pm 0.67 \mathrm{y} ;(\mathrm{t}=3.13 ; p=0.0019)$. On average, the bone ages of $10 \%$ of all prepubertal AA children were two standard deviations above the normative data in the Greulich and Pyle atlas, while the bone ages of $8 \%$ of all prepubertal EA children were two standard deviations below. In contrast to the racial differences observed in prepubertal children, EA postpubertal males had significantly greater values for bone age than AA postpubertal males $(\mathrm{t}=2.03 ; p=$ $0.05)$. The average skeletal age for EA postpubertal males was greater than the chronological age by four months.

\section{DISCUSSION}

Determining skeletal or bone age, as opposed to chronological age, in children is important to learn whether they are growing properly and is especially useful in pediatric endocrinology, orthopedics, forensics, and anthropology (16). The present study was done to determine whether the standards of the Greulich and Pyle atlas are adequate for AA and EA children born after 1980. Our results indicate that variations in skeletal maturation in prepubertal children are greater than those reflected in the Greulich and Pyle atlas, and that there are significant differences in skeletal maturation between American children of European and African descent. Overall, the bone ages of $10 \%$ of the prepubertal AA children are 2 SD above the normative data in the Greulich and Pyle atlas, while around $8 \%$ of the bone ages of prepubertal EA children are 2 SD below these norms. There were also significant differences in skeletal maturation after sexual maturity, and, on average, the bone ages of postpubertal EA males were advanced by three months over those of AA males.

Several methodological issues deserve attention when interpreting our results. Previous studies comparing skeletal and chronological ages in healthy children were limited by the lack of using age-adjusted normal standards for height and weight to verify normal growth in the subjects $(8,9)$. Normality of the study populations was mainly verified by a lack of clinical suspicion of growth abnormalities. The current study was designed to avoid the influence of growth retardation and obesity on skeletal maturation by including only those children with known values of height and weight between the 5th and 95th percentiles for the age-related population. In addition, we determined the degree of sexual maturation of all candidates to account for the confounding effects of puberty on skeletal maturation. Lastly, bone determinations in this study were analyzed by two senior pediatric radiologists to minimize to some extent the subjectivity and intraobserver variability. The strong concordance in readings is a reflection of proficiency and confirms previous studies indicating that bone age estimations improve with clinical experience (17-20).

The present study has two limitations. First, the children enrolled in this study were all from the Los Angeles area, and thus, theoretically, differences between our results and the standards of Greulich and Pyle could in part be due to the effects of geographic location or climatic differences. Second, socioeconomic status was not controlled in this study. However, although extreme situations of poverty and malnourishment are known to lead to pronounced delays in skeletal maturation, the subjects in this study were within the normal percentiles for age-adjusted height and weight (21). Thus, this factor likely had little influence on our results.

This study finds the Greulich and Pyle standards imprecise for American children of European and African descent born after 1980. The U.S.A. is represented by children of all races and accurate methods for bone age determinations are needed for today's children of Hispanic, Asian, and other ethnic backgrounds. To this effect, the development of a hand atlas addressing a diversity of ethnic groups would enhance our ability to determine skeletal maturation with accuracy, reliability, and consistency.

Acknowledgments. The authors would like to thank Mrs. Cara Beck for her technical assistance and comments on this manuscript.

\section{REFERENCES}

1. Tanner JM, Whitehouse RH, Marshall WA 1975 Assessment of Skeletal Maturity and Prediction of Adult Height (TW2 Method). Academic Press, New York

2. Greulich WW, Pyle SI 1959 Radiographic Atlas of Skeletal Development of the Hand and Wrist. 2nd ed. Stanford University Press, Stanford, CA

3. Groell R, Lindbichler F, Riepl T, Gherra L, Roposch A, Fotter R 1999 The reliability of bone age determination in central European children using the Greulich and Pyle method. Br J Radiol 72:461-464

4. Cole AJL, Webb L, Cole TJ 1988 Bone age estimation: a comparison of methods. Br J Radiol 61:683-686

5. Garn SM, Sandusky ST, Nagy JM, McCann MB 1972 Advanced skeletal development in low-income negro children. J Pediatr 80:965-969

6. Marshall WA, Ashcroft MT, Bryan G 1970 Skeletal maturation of the hand and wrist in Jamaican children. Hum Biol 42:421-435

7. MacKay DH 1952 Skeletal maturation in the hand: a study of development in East African children. Trans R Soc Trop Med Hyg 46:135-150

8. Ontell FK, Ivanovic M, Ablin DS, Barlow TW 1996 Bone age in children of diverse ethnicity. Am J Roentenol 167:1395-1398

9. Loder RT, Estle DT, Morrison K, Eggleston D, Fish DN, Greenfield ML, Guire KE 1993 Applicability of the Greulich and Pyle skeletal age standards to black and white children of today. Am J Dis Child 147:1329-1333

10. Karlberg P, Taranger J 1976 The somatic development of children in a Swedish urban community. Acta Paediatr Scand Suppl 258:1-148

11. Behrman RE, Vaughan III VC, Nelson WE 1987 Textbook of Pediatrics. 13th ed. WB Saunders Co., Philadelphia, pp 1185-1186

12. Tanner JM 1978 Physical growth and development. In: Forfar JO, Arnell CC (eds) Textbook of Pediatrics. 2nd ed. Churchill Livingstone, Edinburgh, pp 249-303 
13. Hamill PVV, Drizd TA, Johnson CL, Reed RB, Roche AF, Moore WM 1979 Physical growth: national center for health statistics percentiles. Am J Clin Nutr 32:607-629

14. Vaughan III VC, Litt IF 1987 Developmental pediatrics: assessment of growth and development. In: Behrman RE, Vaughan III VC (eds) Nelson Textbook of Pediatrics. 13th ed. WB Saunders, Philadelphia, pp 24-33

15. Bartko JJ 1966 The intraclass correlation coefficient as a measure of reliability. Psychol Rep 19:3-11

16. Poznanski AK 1984 The Hand in Radiologic Diagnosis with Gamuts and Pattern Profiles. 2nd ed. WB Saunders, Philadelphia

17. Johnson GF, Dorst JP, Kuhn JP, Roche AF, Davila GH 1973 Reliability of skeletal age assessments. Am J Roentgenol 118:320-327
18. Kemperdick HF 1981 Determination of skeletal age in children of Western Germany with normal and abnormal growth development. Fortschr Med 99:152-156

19. King DG, Steventon DM, O'Sullivan MP, Cook AM, Hornsby VP, Jefferson IG, King PR 1994 Reproducibility of bone ages when performed by radiology registrars: an audit of Tanner and Whitehouse II versus Greulich and Pyle methods. Br J Radiol 67:848-851

20. Gross GW, Boone JM, Bishop DM 1995 Pediatric skeletal age: determination with neural networks. Radiology 195:689-695

21. Roche AF 1979 Skeletal maturity of youths 12-17 years: racial geographic area, and socioeconomic differentials, U.S. 1966-70. U.S. Dept. of Health, Education, and Welfare, Washington, DC, Publication 79-1654(11):167 